\title{
Abnormal Situation Management: Detection of Fouling and Longitudinal Bypass in Heat Exchangers
}

\author{
William P. Swan, Dan P. Fernandes, Aniket Khade, and Daniel H. Chen
}

\begin{abstract}
Improved condition monitoring of production equipment enhances process safety and the ability to perform preventive maintenance, thus reduces downtime and associated costs. Condition monitoring or early detection is an integrated part of Abnormal Situation Management (ASM) and is becoming more and more important to chemical process industries due to safety, environmental, and economic reasons. Despite these developments, ASM is generally poorly practiced in the process industries. Much of the actual practice places the onus on plant operators to respond effectively to abnormal conditions. The objective of this article is to plot the data in real time for the detection of fouling in air-cooled exchangers and leaks due to longitudinal bypass in shell and tube heat exchangers. This data is obtained from the Distributive Control System (DCS) historian in the case of shell and tube heat exchanger and experimental methods for air cooled heat exchangers respectively. In this research apparent fouling in one of the shell and tube heat exchanger was actually longitudinal baffle bypass leak.

The methodology used in this study is non-intrusive condition monitoring of the heat exchangers of a petrochemical plant. For the air cooled heat exchangers, the data is obtained by using a hot wire anemometer to measure the air flow and thermocouple wire to measure the temperature of the air for both inlet and outlet conditions respectively. The data got is then analyzed by using heat transfer equations and ASPEN exchanger design program. In the case of shell and tube heat exchangers the flow rate and temperature data of both the shell side and tube side fluid is got from the DCS historian respectively. Then using the heat transfer equations for a shell and tube heat exchanger the data is plotted and analyzed. The results obtained indicate that fouling in the case of air cooled heat exchangers takes place on the air side and is higher in carbon steel tubes than in admiralty. In the case of shell and tube heat exchangers for the BFU type; apparent fouling is actually the longitudinal bypass leak which is severe. For the BEU type fouling, it is due to gum formation and is verified from the data. The schemes for early detection of the above are expected to be a useful for the development of a diagnostic tool for operation alert for ASM and preventive maintenance respectively.
\end{abstract}

Index Terms-Abnormal situation management, fouling, longitudinal baffle leak, heat transfer.

Manuscript received December 5, 2017; revised February 10, 2018. This work was supported by Nexus Engineering, Kingwood, Texas for a multi-year project on "Controller Performance Diagnostics, Process Parameter Identification, and Predictive Maintenance”.

William P. Swan was with SASOL, Lake Charles, Louisiana, USA (email: bswanfamily@aol.com).

Dan P. Fernandes, is with the Center for Abnormal Situation Management Research, Lamar University, Beaumont, Texas 77710, USA (email:dfernandes@lamar.edu).

Aniket Khade and Daniel H. Chen are with the Center for Abnormal Situation Management Research, Lamar University, Beaumont, Texas 77710, USA (email: akhade@lamar.edu, Daniel.chen@lamar.edu).

\section{INTRODUCTION}

Abnormal situation is one where a process variable goes outside its operating envelope or the mechanical integrity of an equipment is undermined and, if not brought under control or remedied, may escalate to an emergency situation (e.g. loss of containment or equipment failure). The causes of process deviation that result in an alarm or interlock activation are not always known in every situation. The process knowledge and experience of the operators has enabled management of many deviations. However, human error or inexperience can result in incorrect diagnosis and incorrect response [1].

Abnormal situation management (ASM) is the job of the operations team to identify the cause of the situation and execute compensatory or corrective actions in a timely and efficient manner. Examples of ASM include fault diagnosis, alarm system management and operator guidance systems [2]. ASM has become especially important as a result of increasing environmental regulation, increasing litigation, and increasing concern by the communities in which refineries and chemical plants are located [3]. Techniques such as real time fault detection and diagnosis (FDD) play a key role in avoiding major accidents, enhancing equipment reliability, and plant profitability. Due to proliferation of historical data, the process history based methods have gained grounds over the model based methods [4].

Real time fault detection and diagnosis (FDD), i.e., condition monitoring, is an important branch of ASM. In this paper, FDD of heat exchangers are presented. Heat exchangers play a critical role in energy-intensive process plants. As such, being able to monitor and detect degrading conditions such as fouling and longitudinal bypass of heat exchangers improves the ability to prepare for necessary maintenance, to perform maintenance more efficiently, and as such, reduce downtime and associated costs [5].

Fouling is a general term referring to any kind of extraneous material that appears upon the heat transfer surface during the lifetime of the heat exchanger. Whatever the cause or exact nature of the deposit, an additional resistance to heat transfer is introduced and the operational capability of the heat exchanger is correspondingly reduced [6]. The growth of fouling depends on composition of the fluids, operating conditions in the heat exchanger, type and characteristics of the heat exchanger, location of fouling, and presence of microorganisms [7]. Detecting heat exchanger fouling is complicated by the fact that overall heat transfer coefficient is a function of the fluid composition and conditions on each side of the heat exchanger. Therefore, the designed duty or temperature approach cannot be compared directly to operating data, as exchangers frequently operate at 
other than designed flow rates and feed conditions.

When air cooled heat exchangers experience reduced air flow, the cooling capacity is reduced especially during warm summer days. This reduction in air flow is due to an increase in the pressure drop across the dirty tube bundle. As the tube bundle gets fouled overtime, the pressure drop will increase gradually leading to reduced air flow around the tubes. The causes of the outer surface of the tube bundle being fouled is due to dirt, rust, leaves or pollen deposition. The reduction in the cooling capacity of the air cooled heat exchanger impacts the production and also causes the distillation column to operate at a higher pressure which is an abnormal situation.

Longitudinal baffles dived a shell into two or more sections, providing multipass on the shell side. But this type should not be used unless baffle is welded to the shell and tube sheet. Nevertheless, several sealing devices have been used to seal the baffle and shell, but none are very effective. If the baffle is not welded, bypassing occurs from one side to the other which adversely affects heat transfer coefficient and makes accurate prediction rather difficult [8].

In this paper, the detection of fouling using non-intrusive conditioning monitoring in fin and shell and tube heat exchangers along with the detection of longitudinal baffle bypass leaks in a shell and tube heat exchanger of a petrochemical plant are discussed. Data collected from the Distributive Control System (DCS) historian were analyzed and graphs that indicate the heat exchanger fouling or a longitudinal bypass were plotted. The information can be integrated in the DCS alarm system along with the diagnosis message.

The proposed method is cost-effective because the conclusion of whether the heat exchanger is fouled or a longitudinal bypass leak occurs can be reached by simply plotting the overall heat transfer coefficient and fouling factor as a function of time in service; based on the operating parameters of the respective heat exchangers obtained from the (DCS) historian and heat transfer equations and ASPEN simulation. The observations of this study were corroborated by the findings of the maintenance personnel when the heat exchangers were opened up during the next available shutdown.

\section{CASE STUdIES}

\section{A. Deterioration of Performance of Air Cooled Heat Exchangers Due to Fouling}

Air-cooled exchangers, also known as fin-fan exchangers, consist of heat exchanger tubes with extended surfaces, commonly referred to as finned tubes [9]. Fans are used to blow air across the finned tubes to provide cooling or heating. Deterioration in operating performance can be due to fouling on the process or air side of the heat exchange surface [10], or due to deterioration in fan performance. Fouling on the airside of the exchanger will adversely affect both heat transfer and air flow.

Four air cooled exchangers in a petrochemical facility used for condensing similar column overheads (condensing temperature between $200^{\circ} \mathrm{F}$ and $300^{\circ} \mathrm{F}$ or $93.3^{\circ} \mathrm{C}$ and 148.8 ${ }^{\circ} \mathrm{C}$ ) were studied. Two of the exchangers were condensers for one distillation column; the other two exchangers were for a second distillation column. All four exchangers had bottom mounted forced airflow fans, with the air flowing up across the tube bundles. The exchangers were between 14 and 40 years old, and the process side of the exchangers did not foul. However, the exchangers were having difficulty during the summer because of the high ambient temperature in being able to condense the column overheads without increasing the operating pressure. The first assumption was that the exchangers were dirty on the air (finned) side, so they were cleaned. The performance did not return to historical operating conditions. The exchanger was then evaluated to determine if the fans and heat exchange tubes were operating as designed.

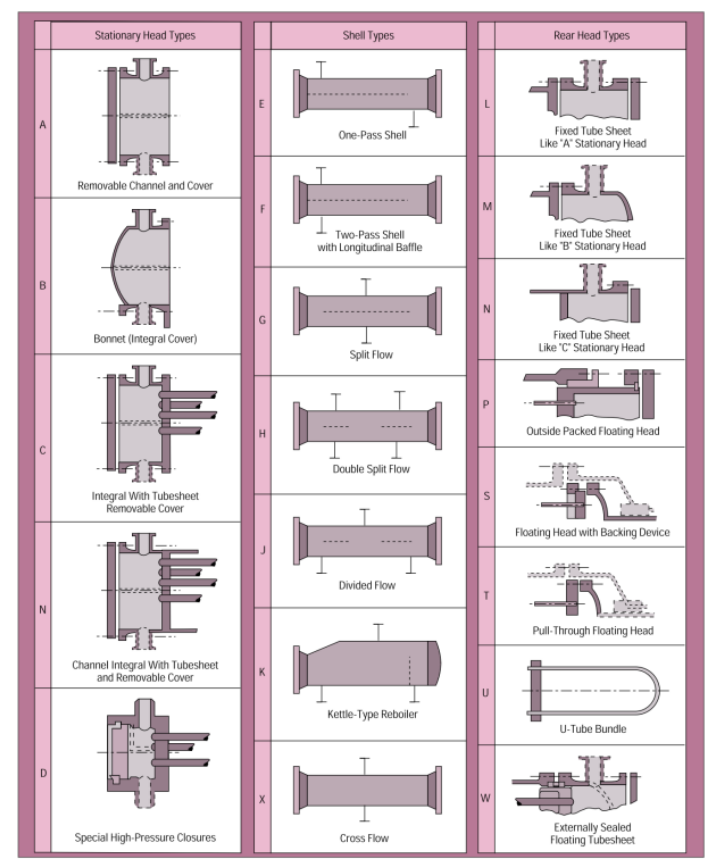

Fig. 1. TEMA designations for shell and tube heat exchangers.

The duty for each exchanger was determined from the air side of the heat exchanger. The air flow was measured in a grid across the fan inlet and across the top surface of the tube bundle using a hot wire anemometer. The air flows measurements were taken on a calm day, as wind would cause errors in the air flow measurements. The temperature of the air supply to the fan and of the air leaving the tube bundle were measured using a length of thermocouple wire attached to a long piece of steel tubing. The inlet temperature for the bundle was assumed to be the average temperature for the fan inlet. The duty for the heat exchanger was calculated as follows:

$$
\begin{gathered}
Q_{\text {air }}=\sum_{1}^{n} Q_{\text {grid }} \\
V_{\text {air }}=v_{\text {air }} * A_{\text {grid }} \\
Q_{\text {grid }}=V_{\text {air }} * \rho_{\text {air }} *\left(T_{\text {out }}-T_{\text {in }}\right)_{\text {fan }}
\end{gathered}
$$

where $Q$ is the heat duty in Btu/hr, $V_{\text {air }}$ is the volumetric flow rate of air in $\mathrm{ft}^{3} / \mathrm{min}, v_{\text {air }}$ is the velocity of air in $\mathrm{ft} / \mathrm{s}, \rho_{\text {air }}$ is the density of air in $\mathrm{lb} / \mathrm{ft}^{3}, C p$ is the heat capacity of the fluid undergoing temperature change in Btu/lb. ${ }^{\circ} \mathrm{F}, T$ is the temperature in ${ }^{\circ} \mathrm{F}$ and $A_{\text {grid }}$ is the area of the grid in $\mathrm{ft}^{2}$.

To check the accuracy of the calculated duty, the sum of the air-side duties for the two exchangers for a given column 
was compared to the process-side duty for the distillation column. The process-side duty was calculated by measuring the reflux and liquid overhead product flows, and multiplying by the enthalpy change from dew point vapor to sub cooled liquid. The air-side and process-side duties agreed within $1 \%$ on one distillation column, and within $7 \%$ on the other distillation column. At this point, the data for the air-side and process-side streams were assumed to be acceptable for further analyses.

$$
\begin{aligned}
Q_{\text {air } 1}+Q_{\text {air } 2} & =Q_{\text {distcolumn }} \\
Q_{\text {distcolumn }} & =\dot{m} *\left(h_{\text {vap }}-h_{\text {liq }}\right) \\
U & =\frac{Q_{\text {air }}}{A * L M T D}
\end{aligned}
$$

$U$ is the overall heat transfer coefficient (Btu/hr- $\left.\mathrm{ft}^{2}-{ }^{0} \mathrm{~F}\right)$. Here $h_{\text {vap }}$ and $h_{\text {liq }}$ are in Btu/lb.

$$
R_{f}=A_{f} *\left(\frac{1}{U * A}-\frac{\ln \left(\frac{r_{0}}{r_{i}}\right)}{2 * \Pi * k * L}\right)
$$

where $R_{f}$ is the fouling factor in ${ }^{0} \mathrm{~F}-\mathrm{ft}^{2}-\mathrm{hr} / \mathrm{Btu}, k$ is the thermal conductivity of the tubes in Btu/hr-ft- ${ }^{0} \mathrm{~F}, r_{0}$ and $r_{i}$ are the outer and inner radius of the tubes respectively in $\mathrm{ft}$ and is $L$ is length of tubes in $\mathrm{ft}$.

Following parameters were determined for the four exchangers:

- Airside-fouling factor was determined using an ASPEN exchanger design and rating program for heat exchanger design and evaluation, B-JAC [11].

- The percent of airside flow was determined by comparing the airside data and design data for the exchangers.

ASPEN's heat exchanger program was used with the input of the exchanger configuration (tubes, fins, rows), the measured duty (average of the process side duty and the air side duty), and the measured process and air temperatures, as well as the process composition. The ASPEN heat exchanger program used the temperatures and exchanger configuration to calculate the area and the corrected log mean temperature difference.

\section{B. Deterioration of Performance of Shell and Tube Heat Exchanger Due to Fouling/Longitudinal Bypass Leak}

Four shell and tube heat exchangers in a hydro treater unit of a petrochemical facility were evaluated to demonstrate how the fouling of exchangers could be tracked. These exchangers are known to require periodic cleaning, and have varying flow rates and compositions. Three of the exchangers are BFU (Bonnet front end stationary head; F shell type; U-tube bundle rear end stationary head) type exchangers; counter flow exchangers with two passes on the shell side and two passes on the tube side. The other exchanger is a BEU (Bonnet front end stationary head; E shell type; U-tube bundle rear end stationary head) type exchanger with two passes on the tube side, but only one pass through the shell side.

The first type exchanger to be evaluated for fouling was a BFU type exchanger with a gas flowing on the cold shell side and a condensing liquid-gas mixture on the hot tube side. The following daily average data were collected for a three-year period using a process information (data logger) system:
- Gas flow rate

- Liquid flow rate

- Shell side (gas) inlet and outlet temperature

- Tube side (two phase) inlet and outlet temperature

The heat capacity data for the shell side gas were determined from an ASPEN simulation [11] for the gas compositions. The change in enthalpy per unit mass per unit change in temperature were determined for the two-phase flow using the duty determined from the shell side of the exchanger for 300 days of data.

$$
\begin{gathered}
Q_{\text {hot }}=Q_{\text {cold }} \\
\dot{m}_{h} * C_{p h} *\left(T_{\text {in }}-T_{\text {out }}\right)_{h}=\dot{m}_{c} * C_{p c} *\left(t_{\text {out }}-t_{\text {in }}\right)_{c}
\end{gathered}
$$

where $\dot{m}_{h}$ and $\dot{m}_{c}$ are mass flow rate in $\mathrm{lb} / \mathrm{hr}$ for hot and cold side respectively, $C_{p h}$ and $C_{p c}$ are heat capacity in Btu/lb. ${ }^{\circ} \mathrm{F}$ for hot and cold side respectively and $T$ and $t$ is the temperature of hot and cold fluid respectively in ${ }^{\circ} \mathrm{F}$.

Then the duty and the log mean temperature difference (LMTD) was calculated for each day.

$$
\left.L M T D=\frac{\left(\Delta_{T 1}-\Delta_{T 2}\right)}{\ln \left(\frac{\Delta_{T 1}}{\Delta_{T 2}}\right)}\right)
$$

The actual (dirty) overall heat transfer coefficient can be determined from

$$
U_{\text {dirty }}=\frac{Q}{A * L M T D}
$$

$U$ is the overall heat transfer coefficient in Btu/hr- $\mathrm{ft}^{2}-{ }^{\circ} \mathrm{F}$

The value for the clean overall heat transfer coefficient $\left(U_{\text {clean }}\right)$ can be determined from the shell-side and tube-side heat transfer coefficients at different flow rates and composition, but keeping at design temperatures.

$$
\begin{gathered}
\frac{1}{U_{\text {clean }}}=\frac{1}{h_{o}}+\frac{1}{h_{i}} * \frac{d_{o}}{d_{i}}+r o * \frac{\ln \left(\frac{r_{o}}{r_{i}}\right)}{k} \\
\frac{h_{i * d}}{k}=0.023 *\left(R_{e}\right)^{0.8} * \operatorname{Pr}^{\frac{1}{3}} *\left(\frac{\mu_{b}}{\mu_{w}}\right)^{0.14}
\end{gathered}
$$

The above equation is the Sider-Tate equation which is used to calculate the tube side heat transfer coefficient. Here $h_{i}$ is the tube side heat transfer coefficient in Btu/hr-ft ${ }^{2}-\mathrm{F}$. $k$ is the thermal conductivity of the tube in Btu/hr-ft- ${ }^{\circ}$. Re is the Reynolds number and $\operatorname{Pr}$ is the Prandlt number. $\mu_{b}$ and $\mu_{w}$ are the viscosity in the bulk and wall respectively in $\mathrm{cP}\left(\mathrm{lbf} . \mathrm{s} / \mathrm{ft}^{2}\right)$.

The shell side heat transfer coefficient is calculated by the modified Donohue equation as given below

$$
h_{o} * \frac{D_{e}}{k}=0.36 *(R e)^{0.55} * \operatorname{Pr}^{\frac{1}{3}} *\left(\frac{\mu_{b}}{\mu_{w}}\right)^{0.14}
$$

Here $h_{o}$ is the shell side heat transfer coefficient in $\mathrm{Btu} / \mathrm{hr}-\mathrm{ft}^{2}-{ }^{\circ} \mathrm{F} . D_{e}$ is the hydraulic diameter of the shell side in feet.

The fouling factor $\left(R_{f}\right)$ is calculated by the equation:

$$
R f=\left(\frac{1}{U_{\text {dirty }}}-\frac{1}{U_{\text {clean }}}\right)
$$

$R_{f}$ is the fouling factor in ${ }^{\circ} \mathrm{F}-\mathrm{ft}^{2}-\mathrm{hr} / \mathrm{Btu}$

The apparent fraction bypassing the longitudinal baffle can be determined by assuming there is no fouling. Then, use the design flow rate of the heat exchanger and the clean overall 
heat transfer coefficient to calculate the LMTD for clean conditions. From this LMTD calculation, the theoretical outlet temperature of the gas can be calculated. If the exchanger had the clean overall coefficient, the outlet temperature on the cold shell side would be essentially the same as the inlet on the hot tube side; in order to give the LMTD calculated from

$$
L M T D_{\text {clean }}=\frac{Q}{A * U_{\text {clean }}}
$$

$$
\begin{aligned}
& \text { Fraction of Bypassing Liquid }= \\
& \quad 1-\frac{\text { (actual temperature of the gas })}{(\text { Theoretical temperature of the gas })}
\end{aligned}
$$

The second type exchanger to be evaluated is a BEU type, with two tube passes (through the U-tubes), one shell side pass and heat is exchanged between a cold hydrocarbon feedstock and the condensing overhead vapors of a distillation column. The following daily average data were collected for a three-year period using a process information (data logger) system:

- Liquid (shell-side) flow rate

- Distillation tower overhead product flow rate

- Distillation tower reflux flow rate

- Tube side (two phase) inlet and outlet temperature

- Shell side (liquid) inlet and outlet temperature

The duty can be determined from the shell side duty using the increase in sensible heat for the liquid stream on the shell side. The LMTD can be determined from the four process temperatures. The LMTD correction factor $(F)$ for the absence of true counter flow can be obtained from the available charts in the literature.

$$
U_{\text {dirty }}=\frac{Q}{A * L M T D * F}
$$

The third type of exchangers to be evaluated next were five BFU type exchangers, with U-tubes and longitudinal baffles on the tube side to provide true counter flow. The exchangers were divided into two groups; one group is a pair of heat exchangers at lower temperatures and the other group was a trio at higher temperatures. The following daily average data were collected for a three-year period using a process data from the historian:

- Liquid (shell-side) flow rate

- Vapor flow rate (combines with liquid to provide two-phase flow)

- Tube side (two phase) inlet and outlet temperature (overall)

- Shell side (liquid) inlet and outlet temperature (overall and intermediate)

\section{RESUlts AND Discussion}

\section{A. Results of the Performance of Air Cooled Heat Exchangers}

The exchangers were found to have both lower heat transfer and air flow than originally designed. However, the oldest exchanger had the best heat transfer, but had a different tube material than the other exchangers. Fig. 2 shows the effect of age on the fouling factor for the exchangers. The fouling factor is based on the surface area of the bare tubes. It shows that the fouling factor for the carbon steel tubes is higher. The fouling factors are higher than expected. According to Perry's Handbook for Chemical Engineers [12] and the GPSA Engineering Data Book [13], the air-side fouling factor should be negligible. However, as shown in Fig. 2, after ten years the fouling factor can become appreciable. Operation experience indicates that air cooled exchangers are often operated in excess of ten years, indeed even as much as 40 years. Air cooled exchanger vendors recommend the replacement of air finned exchangers every ten years as it is a typical design life for air-cooled exchangers. The oldest exchanger had lower fouling factor due to the tubes made of admiralty, rather than carbon steel. This exchanger was visually cleaner than the other exchangers, as well. The reason admiralty performed better may be due to corrosion (rust) that forms on the carbon steel tubes over time which lowers the air velocity and reduces the heat removal rate of the air cooled heat exchanger. This observation suggests that admiralty would be a better choice compared to carbon steel for new tube bundles in this service. However, admiralty should not have been used in this case as it has a lower melting point than carbon steel and the process material is flammable. The airflow as a percent of design is shown in Fig. 3. Again, the performance declines over time, except for the exchanger with admiralty tubes.

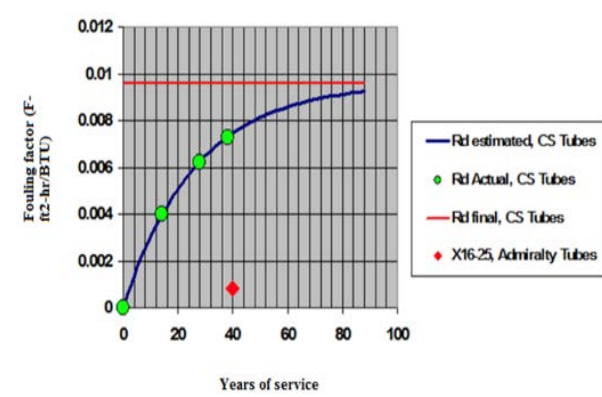

Fig. 2. Fouling factor in air cooled heat exchangers.

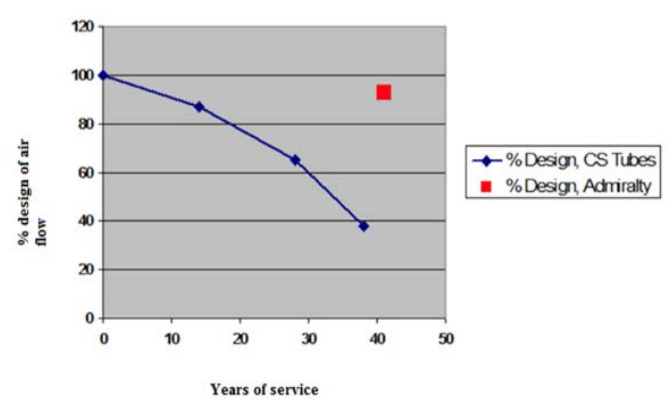

Fig. 3. Air flow through an air-cooled heat exchanger.

The results show that the exchangers had experienced a slow decline over time, and that, at a minimum, new tube bundles would eventually be required for the exchangers with carbon steel tubes. The exchanger with admiralty tubes would also require replacement, but the exchanger size would have to be increased to compensate for poorer performance as the exchanger aged.

\section{B. Results of the Performance of the Shell and Tube Heat Exchangers}

Fig. 4. shows for a gas/condensing two phase BFU the value of $U_{\text {clean }}$ declines steadily with time, as does the actual $U_{\text {dirty }}$ heat transfer coefficient. The reason for $U_{\text {clean }}$ 
decreasing is to account for the changes in the gas composition and flow rates. Fig. 5 shows that the fouling factor increases steadily during the three-year period. The exchanger does have the potential for the shell-side gas to "short-circuit" the desired flow path. The shell-side gas flow is likely to bypass the desired flow path if there are any leak points on the longitudinal baffle, or if the pressure difference at the leak point is excessive. The apparent fouling factor as shown in Fig. 6 may actually be a measure of baffle leakage that reduces the amount of heat exchange, or a combination of fouling and leakage.

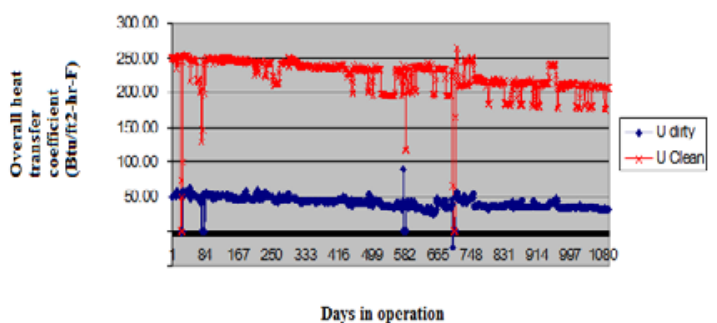

Fig. 4. Overall heat transfer coefficient for clean and dirty conditions for the gas/condensing two phase BFU heat exchanger.

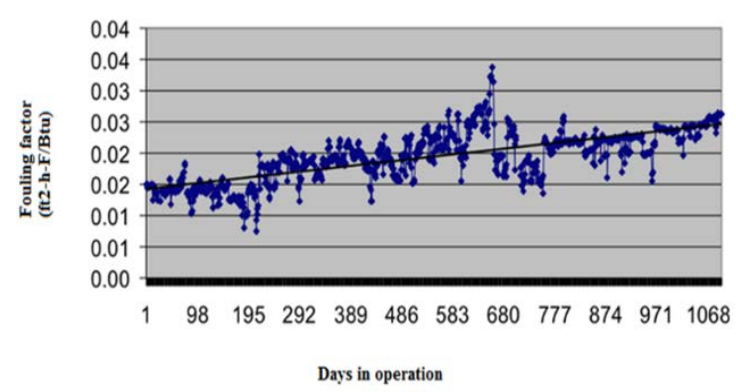

Fig. 5. Fouling factor for the gas/condensing two phase BFU heat exchanger.

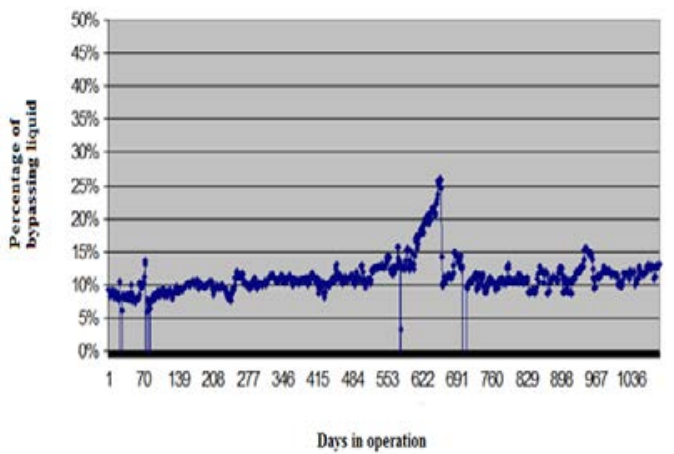

Fig. 6. Apparent percentage of liquid bypassing in the gas/ condensing two phase BFU heat exchanger.

Fig. 7 shows that the fouling factor for the liquid / condensing two-phase flow BEU exchanger increases with time. However, this exchanger has been found to foul and is difficult to clean except during lengthy, planned outages. The mechanism for fouling is believed to be related to the formation of heavies called "gums." The hydrocarbon liquid feed contains gums, as well oxygenates that can form gums at elevated temperatures which occurs in the exchanger system. Fig. 7 appears to have two regions for the graph of $R_{f}$ versus cumulative feed. The first region is fairly flat, and may be due to existent gums in the feed being deposited in exchangers upstream. The second region has a greater slope, and may be due to breakthrough of existent gums from exchangers upstream.

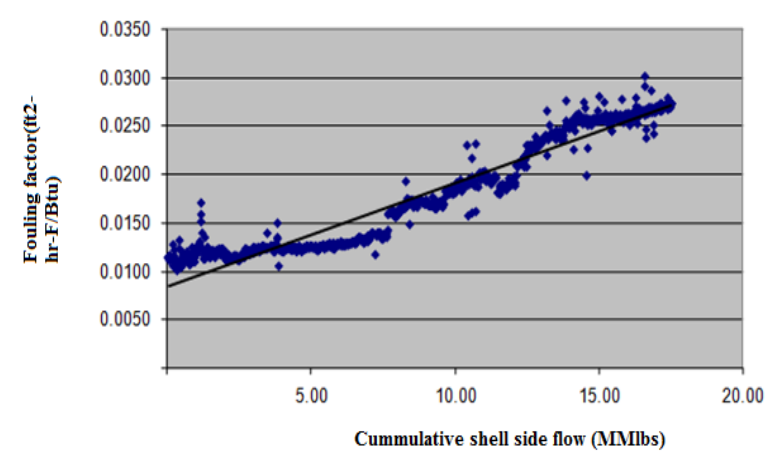

Fig. 7. Fouling factor for liquid/condensing two-phase BEU heat exchanger.

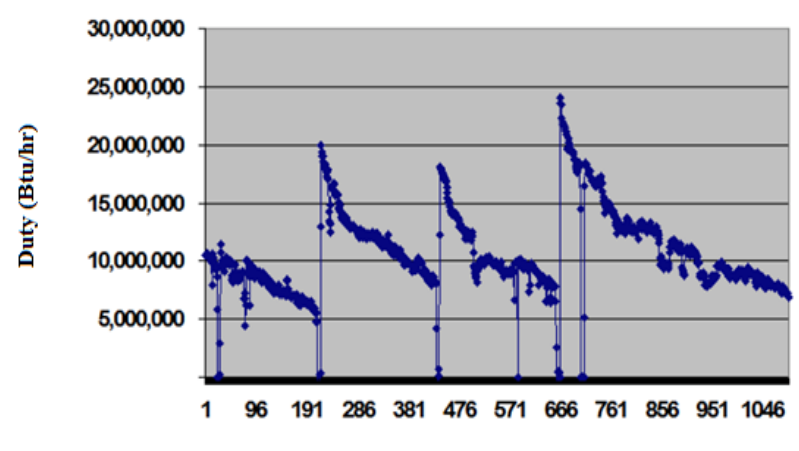

Days in operation

Fig. 8. Heat duty for the low pair temperature BFU heat exchangers with counter flow liquid and condensing two phase flow.

From Fig. 8, it can see that the duty drops off gradually, then abruptly increases for the low temperature pair heat exchangers. The abrupt increases occur when the exchangers are cleaned. The fouling factor for these exchangers is shown in Fig. 9. These values start at a high value, when compared to the literature. The final values are two orders of magnitude ( 0.13 vs. 0.0013 ) greater than literature values [9]. The linear shape of the fouling curve versus time fits the trend expected in literature [10]. These exchangers were F shell exchangers, with a longitudinal baffle to ensure counter flow of the shell-side liquid with the flow through the U-tubes. As with the gas and condensing two-phase fluid exchanger, the shell side liquid may be leaking across the longitudinal baffle. Per literature [14]-[15] the pressure drop across the longitudinal baffle should not exceed $5-7$ psi (0.344-0.48 bar). These exchangers had shell-side pressure drops of 8-20 psi (0.55-1.377 bar), so leakage across the longitudinal baffle was to be expected. This problem likely explains why these exchangers, when clean, do not have overall heat transfer coefficient close to $U_{\text {clean }}$.

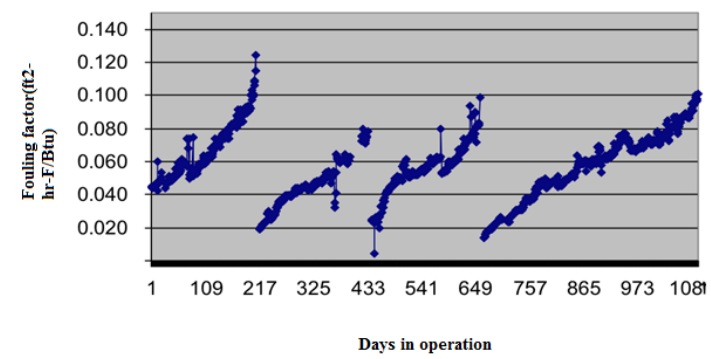

Fig. 9. Fouling factor for the low pair temperature BFU counter flow heat exchangers with liquid exchanging heat with condensing two phase flow.

Fig. 10 shows the apparent heat transfer coefficients if $38 \%$ 
of the shell-side fluid is bypassing the longitudinal baffle. The 38\% bypassing was determined by "trial and error," until the $U_{\text {dirty }}$ matched $U_{\text {clean }}$ right after clean exchangers were returned to service. Although this amount of leakage seems very excessive, the literature [15] describes that a gap in the longitudinal seals of only 0.01 inches can result in $100 \%$ fluid bypassing. The fouling also seems extremely rapid after return to service; which would lead to believe that the exchangers may not be truly "clean" when cleaned. The rapid fouling when the exchanger is clean is due to the high tube surface temperatures and the fouling mechanism (polymerization or coking). Fig. 11 shows the heat duty of the trio high temperature heat exchangers. These exchangers do not show the degree of fouling as the low temperature pair heat exchangers. This result suggest that the mechanism of fouling is related to trace materials that are heat sensitive (polymerizing or coking near hot metal) which break down at these higher temperatures.

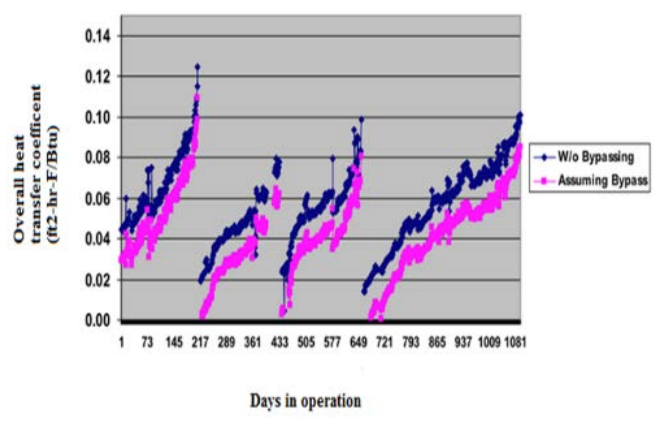

Fig. 10. Apparent heat transfer coefficients with an assumed $38 \%$ of shell side fluid bypassing for the low temperature pair BFU heat exchanger with counter flow liquid and condensing two phase flow.

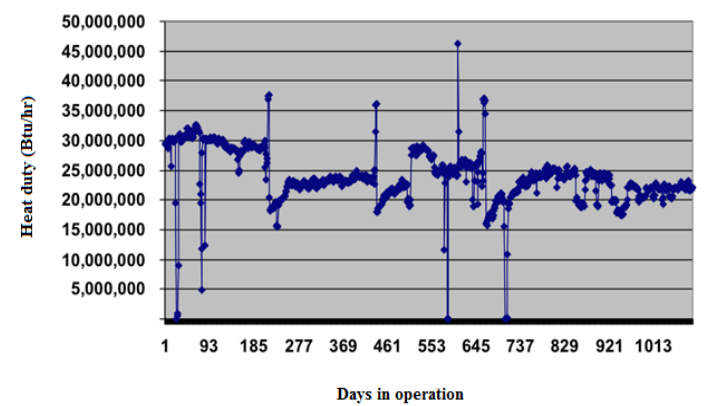

Fig. 11. Heat transfer duty for the high temperature trio BFU heat exchangers with counter flow liquid and condensing two- phase flow.

The clean overall heat transfer coefficient for both the shell side and tube side fluids were adjusted for changes in composition and flowrate. An understanding of the flow regime is a must to ensure these adjustments are made correctly. If the exchanger has an F shell (with two pass flows and a longitudinal baffle), the potential for bypassing of the longitudinal baffle must be evaluated.

\section{CONCLUSION}

The experimental grid method for air cooled heat exchanger data collection and the DCS historian for shell and tube heat exchanger along with the analysis must be accurate; since bad data can be obtained due to faulty sensors or incorrect measurement techniques. Fouling in air cooled heat exchangers is mostly on the process air side and is due to rust formation in carbon steel tube. It is interesting to note that the apparent fouling factors for $\mathrm{F}$ shell exchangers may actually be poor heat transfer due to bypassing of the longitudinal baffle. Further scope of studies exits in automating the collection of data for the grid method in air cooled heat exchangers and also for a software to distinguish between longitudinal bypass leaks and fouling in shell and tube heat exchangers. Subsequently, a screen based interactive FDD tool with diagnostic information can be developed for monitoring and preventive maintenance purposes.

\section{REFERENCES}

[1] R. Ramen and I. Cameron, "Abnormal situation management in process control: Do we have it under control?,” presented at the 7th World Congress of Chemical Engineering, Glasgow, Scotland, pp. 10-14, July 2005.

[2] Brooks, Robin, R. Thorpe, and J. Wilson., "A new method for defining and managing process alarms and for correcting process operation when an alarm occurs," Journal of Hazardous Materials, vol. 115, no. 1-3, pp. 169-174, 2004.

[3] Nimmo and Ian., "Industry initiative addresses abnormal events, hydrocarbon processing,” vol. 77, issue 10, pp. 71-80, 1998.

[4] Y. Shu, L. Ming, F. Cheng, Z. Zhang, and J. Zhao, “Abnormal situation management: Challenges and opportunities in big data era,” Journal of Computers and Chemical Engineering, vol. 91, pp. 104-113, August 2016.

[5] I. B. Utne, T. Brurok, and H. Rodseth, "A structured approach to condition monitoring," Journal of Loss Prevention in the Process Industries, vol. 25, pp. 478-488, 2011.

[6] J. R. Thome, Engineering Data Hand Book 3, Wolverine Tube Inc., p. 47, 2004.

[7] O. Gudmundsson, O. P. Palsson, H. Palsson, and S. Lalot, " Online fouling detection of domestic hot water heat exchangers," Journal of Heat Transfer Engineering, vol. 37, no. 15, p. 1231, 2016.

[8] K. Thulukknam, Heat Exchanger Design Handbook, 2nd ed., Boca Raton, Fl: CRC press, 2013, p. 249.

[9] P. D. Hills, Practical Heat Transfer, New York: Begell House, 2005.

[10] A. K. Sheikh, S. M. Zubair, M. Younas, and M. O. Budair, "Statistical aspects of fouling processes," in Proc. the Institution of Mechanical Engineers, vol. 215, 2001, pp. 331-355.

[11] BJAC exchanger design help manual. ( 2003). ASPEN Technology Inc. [Online]. Available: http://aspentech.com/products/aspen-tascplus.

[12] H. R. Perry and H. C. Chilton, Chemical Engineers Handbook, 8th ed., McGraw-Hill Book Company., 2007.

[13] Gas Processors Suppliers Association, GPSA Engineering Data Book, 13th ed., 2012.

[14] M. Rajiv, "Does your application call for an F-shell heat exchanger?" Chemical Engineering Progress, vol. 100, no. 4, pp. 40-45, 2004.

[15] T. Rozenman and J. Taborek, "The effect of leakage through the longitudinal baffle on the performance of two-pass shell exchangers," AIChE Symposium Series Heat Transfer, vol. 118, pp. 12-20, 1971.

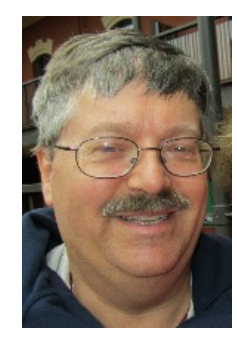

Bill Swan served as a technology manager for Sasol North America's Lake Charles chemical complex. He has a BS degree in chemical engineering from Michigan Tech, and an MEng degree in chemical engineering and an MBA from McNeese State University. Mr. Swan has 37 years' experience in the petrochemical industry in process engineering, operations, distribution and management. He started with Conoco chemicals and ultimately retired from SASOL.

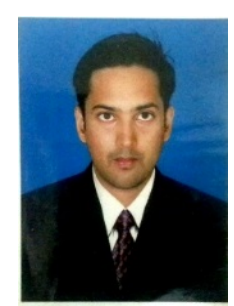

Dan Philip Fernandes is a $\mathrm{PhD}$ student at Lamar University, received his bachelor's degree from Visveswarya Technological University in India (2007) in chemical engineering. He worked as a process engineer in a fertilizer plant (2007-11) and applications engineer in rotating equipment (2011-2013). Current research interests are abnormal situation management in process equipments using data analytics and applications to smart chemical plant operations. Dan is a member of AIChE. 


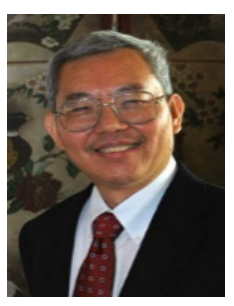

Daniel H. Chen is a university professor and scholar, and the holder of Leland Best Distinguished Faculty Fellow, at Lamar University, Beaumont, Texas. He has a B.S. degree from National Cheng Kung University, a MS degree from National Taiwan University and a $\mathrm{PhD}$ degree, from Oklahoma State University in chemical engineering. Dr. Chen's areas of expertise are process control, air pollution control, and abnormal situation management.

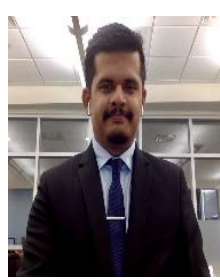

Aniket Khade is a $\mathrm{PhD}$ student at the Dan F. Smith Department of Chemical Engineering, Lamar University, holds a bachelor's degree in chemical engineering from Pune University, India. His current research interests include real time condition monitoring and abnormal situation management in Chemical Industries using smart sensors and data analytics. 